\title{
Typeability of MALDI-TOF assay for identification of non-aureus staphylococci associated with bovine intramammary infections and teat apex colonization
}

\author{
Yasser S. Mahmmod, ${ }^{+} \dagger^{1,2}$ Bettina Nonnemann, $\ddagger$ Line Svennesen, ${ }^{*}$ Karl Pedersen, $\ddagger$ and Ilka Christine Klaas ${ }^{* 3}$ \\ *Department of Veterinary and Animal Sciences, Faculty of Health and Medical Sciences, University of Copenhagen, 1870 Frederiksberg C, \\ Denmark \\ †Infectious Diseases, Department of Animal Medicine, Faculty of Veterinary Medicine, Zagazig University, 44511-Zagazig, Sharkia Province, \\ Egypt \\ ‡National Veterinary Institute, Technical University of Denmark, 2800 Kongens Lyngby, Denmark
}

\begin{abstract}
Matrix-assisted laser desorption/ionization time of flight (MALDI-TOF), a culture-dependent assay, has recently been implemented for routine identification of non-aureus staphylococci (NAS) species from milk, but the assay has never been investigated for NAS from nonmilk or environmental samples. The objective of this study was to evaluate the typeability of the MALDITOF assay for the identification and differentiation of bovine-associated NAS species on aseptically collected quarter milk and teat skin samples in dairy herds. In 8 herds, 14 to 20 cows with elevated somatic cell count were randomly selected for teat skin swabs and foremilk samples from right hind and left front quarters. Teat skin swabs and milk samples were collected aseptically for preliminary identification using bacterial culture on chromogenic and calf blood agars. Colonies from milk and teat skin samples with suspicion of having NAS were identified to species-level by MALDITOF assay. Out of 511 isolates from 284 quarters (142 cows), $78 \%$ ( $\mathrm{n}=399$ ) were identified by MALDI-TOF. The percentage of correctly identified NAS from milk (91\%, 105/115) using MALDI-TOF was higher than the percentage from teat skin $(68 \%, 268 / 396)$. Out of the identified isolates, $93 \%(\mathrm{n}=373)$ were successfully identified as NAS, whereas the remaining $26(7 \%)$ were shown to be other bacterial species. Out of 26 NAS isolates, 1 originated from milk (Corynebacterium stationis), whereas 25 originated from teat skin representing Aerococcus viridans $(\mathrm{n}=7)$, Bacillus pumilus $(\mathrm{n}=$
\end{abstract}

\footnotetext{
Received February 12, 2018.

Accepted June 25, 2018.

${ }^{1}$ Corresponding author: yasser@sund.ku.dk, yasser.mahmmod@irta .cat, or yasserpcr@gmail.com

${ }^{2}$ Present address: IRTA, Centre de Recerca en Sanitat Animal (CReSA, IRTA-UAB), Campus de la Universitat Autònoma de Barcelona, 08193 Bellaterra, Barcelona, Spain.

${ }^{3}$ Present address: DeLaval International AB, 14721 Tumba, Sweden.
}

13), Enterococcus saccharolyticus $(\mathrm{n}=1)$, Clostridium septicum $(\mathrm{n}=1)$, Corynebacterium stationis $(\mathrm{n}=2)$, and Corynebacterium casei $(\mathrm{n}=1)$. The MALDI-TOF identified $85(98 / 115)$ and $62 \%(245 / 396)$ of the isolates in the first test. Isolates that were not identified to species-level at first test were subjected to a second test, and 47 (8/17) and 32\% (48/151) from milk and teat skin, respectively, were identified. After 2 rounds of MALDI-TOF, $22 \%(\mathrm{n}=112)$ of the isolates were not identified, representing 103 from teat skin and 9 from milk. Eighteen isolates without identification by MALDI-TOF were successfully identified to specieslevel using sequencing, where 16 were correctly identified as NAS, whereas the other 2 were Corynebacterium stationis. In conclusion, MALDI-TOF is a reliable assay for identification and typeability of NAS species from aseptically collected quarter milk samples. The assay may be used for identification of NAS species from teat skin swabs. However, confirmation using nucleic acidbased tools is vital for accurate species identification of some species and strains.

Key words: non-aureus staphylococci, bovine mastitis, teat skin colonization, phenotypic identification

\section{INTRODUCTION}

Non-aureus staphylococci (NAS) are a heterogeneous group of bacterial species (Schukken et al., 2009) regarded as a common cause of IMI in dairy herds (Zadoks and Watts, 2009). Moreover, NAS abundantly colonize the teat skin, teat apex, and teat canal and, hence, many studies have shown that teat colonization with NAS could have a significant role in initiation or development of IMI with NAS in dairy cows (Leroy et al., 2015; De Visscher et al., 2016). Recent studies documented that some species are more important than others in relation to udder health (Supré et al., 2011; De Visscher et al., 2016). Furthermore, De Visscher et al. (2014) provided evidence that NAS species are 
composed of environmental, opportunistic, and hostadapted species, which differ in ecology. Additionally, those authors concluded that some extramammary niches, such as the teat apex, might act as infection sources for IMI-causing NAS. Except for Staphylococcus xylosus, an association was observed between teat canal colonization and IMI by all NAS species, in which the majority of IMI were preceded by teat canal colonization (Quirk et al., 2012).

Non-aureus staphylococci are known to be a common teat apex colonizer (Braem et al., 2013; Falentin et al., 2016) and are among the mastitis-causing bacteria most likely to enter the mammary gland through the teat orifice (Fox and Norell, 1994), resulting in the establishment of IMI (Pyörälä and Taponen, 2009; Piepers et al., 2010). Braem et al. (2012) identified staphylococci among the bacterial genera with the highest percentage $(31 \%)$ of colonized teat apices, and they were detected with equal prevalence from teat apices of noninfected, subclinically infected, and clinically infected quarters. Therefore, it is crucial to identify and differentiate the NAS species colonizing teat skin or inhabiting milk that cause IMI to understand their epidemiology and to evaluate the clinical relevance and feasibility of speciesspecific infection control measures (Zadoks and Watts, 2009). Furthermore, routine microbiological testing is important, because rapid and correct identification of mastitis-causing pathogens will influence the choice of antibiotic before the final determination of antibiotic resistance of the isolate (Nagy et al., 2014). For many years, the species identification of NAS relied on phenotypic characteristics, which is difficult, time-consuming, laborious, and often inaccurate (Watts et al., 1991; Vanderhaeghen et al., 2014). Although biochemical assays such as analytical profile index systems are widely used for identification of NAS, the accuracy and speed is not optimal (Taponen et al., 2006; Capurro et al., 2009; Sampimon et al., 2009; Park et al., 2011).

Matrix-assisted laser desorption/ionization time of flight (MALDI-TOF) mass spectrometry is a rapid method that is able to identify a great variety of isolated bacteria based on the composition of conserved ribosomal proteins (Kliem and Sauer, 2012). This technique is based on the acquisition of protein (ribosomal proteins) fingerprints directly from intact microorganisms, as such profiles vary considerably among microorganisms (Singhal et al., 2015). The assay provides a new diagnostic platform that overcomes the limitations of traditional diagnostics for NAS, being time-consuming and laborious, or the need of sugar fermentation or test kits (Watts et al., 1991; Capurro et al., 2009; Vanderhaeghen et al., 2014; Taponen et al., 2016). The technique is increasingly used in human medicine and, recently, it has been expanded as a routine diagnostic tool in veterinary medicine (Randall et al., 2015; Pizauro et al., 2017). In recent years, research studies showed that MALDI-TOF is a powerful and reliable diagnostic tool for identification and discrimination of mastitiscausing pathogens, including NAS from bovine mastitis samples (Tomazi et al., 2014; Gonçalves et al., 2014; Cameron et al., 2017, 2018) and spiked milk samples (Barreiro et al., 2017). The MALDI-TOF assay was validated against other routine diagnostics for NAS, such as the Vitek 2 compact system (Elbehiry et al., 2016) and PCR (Pizauro et al., 2017), where it showed a better performance in identification and discrimination of NAS species from bovine mastitis. To the best of our knowledge, no literature is available describing the performance of MALDI-TOF assay for identification of NAS from nonmilk cow samples or environmental samples in dairy herds. The objective of our study was to evaluate the typeability of the MALDI-TOF assay for the identification and differentiation of bovine-associated NAS species on quarter level from aseptically collected milk (IMI) and teat skin (teat apex colonization) habitats in dairy herds.

\section{MATERIALS AND METHODS}

\section{Study Population}

Eight dairy herds with Danish Holstein cows were selected to participate in a project on Streptococcus agalactiae and Staphylococcus aureus IMI. To be eligible for inclusion in the present study, herds had to have automatic milking systems with $\geq 3$ milking robots and bulk tank milk PCR cycle threshold value $\leq 32$ for Streptococcus agalactiae. About 30 to 40 lactating dairy cows were selected randomly from each herd on the basis of the criteria of having no clinical mastitis, SCC $\geq 200,000$ cells $/ \mathrm{mL}$ at the preceding milk recording, and not subjected to antibiotic therapy during the $4 \mathrm{wk}$ before sample collection. From each cow with an odd laboratory running number, teat skin swab and aseptic milk samples were taken from right hind and left front quarters (Mahmmod et al., 2018).

\section{Sampling Procedures}

Each herd was visited once to collect teat swab samples and aseptically collected quarter foremilk samples for bacterial culture. The farmers were asked to separate the selected cows for sampling. Cows were fixed in head lockers or tied. Teat swab samples were collected according to the modified wet-dry method (Paduch et al., 2013). Briefly, the teat skin was sampled after cleaning with dry tissue paper. The first rayon swab (DaklaPack, Glostrup, Denmark) was moistened with 
1/4 Ringer's solution (Merck, Darmstadt, Germany) and rotated $360^{\circ}$ around the teat about $1 \mathrm{~cm}$ from the teat canal orifice. The same procedure was carried out with a dry swab (second). Immediately after sampling, the tips of both swabs were transferred into 1 tube with $2 \mathrm{~mL}$ of sterile $1 / 4$ Ringer's solution.

Quarter milk samples were collected directly after harvesting the teat swab samples according to National Mastitis Council (1999) guidelines. Briefly, the teat end was thoroughly disinfected with cotton swabs drenched with ethanol (70\%). Individual quarter foremilk samples were then aseptically collected in sterile screw-cap plastic tubes. New latex gloves were worn at each sampling procedure and were changed after each cow. Tubes containing the teat swabs and aseptically collected milk samples were stored at $5^{\circ} \mathrm{C}$ in coolers with ice packs until the samples were delivered to the microbiological laboratory within $24 \mathrm{~h}$. All study activities, including farm visits, collection of samples and laboratory examination, were carried out during the period from February to May 2017.

\section{Laboratory Procedures}

Bacteriological Examination. Bacterial culture for milk samples was conducted in accordance with National Mastitis Council (1999) recommendations. After vortexing, $0.01 \mathrm{~mL}$ of the milk sample from each quarter was streaked using disposable, calibrated bacterial loops on a calf blood agar plate; simultaneously, another $0.01 \mathrm{~mL}$ of the same sample was streaked on chromogenic agar plates selective for staphylococci species (SASelect, Bio-Rad, Marnes-la-Coquette, France). Bacterial culture of teat swab samples was performed according to the procedures of Paduch et al. (2013). Briefly, the teat swab sample was vortexed before removing the swab tips from the tubes. The agar plates were inoculated with $0.1 \mathrm{~mL}$ of a swab solution prepared with 1/4 Ringer's solution. The inoculum was spread with a sterile Drigalski spatula onto the agar surface of a calf blood agar plate and SASelect media simultaneously for each quarter.

All the inoculated plates were marked by the laboratory running number and sequence of the quarter, incubated aerobically at $37^{\circ} \mathrm{C}$ for $48 \mathrm{~h}$, and examined for growth of NAS colonies after 24 and $48 \mathrm{~h}$. Staphylococcus species were presumptively identified on the basis of the phenotypic characteristics of their colonies, including shape (round, glossy) and color on the selective media. Up to 3 different NAS species per sample, according to the colony color on the SASelect media, were considered for further identification at species level. A cutoff $\geq 5$ cfu on the plate was regarded as an acceptable cutoff point for defining the positivity of
NAS according to Thorberg et al. (2009) from milk and teat skin samples based on bacterial culture.

MALDI-TOF Assay and Species Identification. Isolates of NAS species that were identified based on bacterial culture were subcultured individually on new calf blood agar plates and incubated for $24 \mathrm{~h}$ at $37^{\circ} \mathrm{C}$ to be submitted freshly to MALDI-TOF Bruker Biotyper software system (Microflex LT, Bruker Daltonics GmbH, Bremen, Germany) using an Autoflex Speed for identification of NAS at species level. The bacteria were prepared for MS analysis according to a standard extraction protocol using formic acid (Bizzini et al., 2010), as recommended by the manufacturer. A sterile wooden applicator was used to pick the material from a single bacterial colony followed by smearing a thin film of colony material onto a MTP 384 ground steel target plate (Bruker Daltonics). Subsequently, each spot was overlaid with $1.0 \mu \mathrm{L}$ of a saturated Q-cyano-4-hydroxycinnamic acid in 50\% acetonitrile and 2.5\% trifluoroacetic acid solution and air-dried at room temperature. Mass spectra were obtained on an Autoflex Speed calibrated with the recommended Bruker Escherichia coli bacterial test standard for MS.

Spectra of the analyzed bacteria were obtained in positive linear mode, within the mass range of 2 to 20 $\mathrm{kDa}$. Spectra were acquired using the flexControl 3.4 program (Bruker Daltonics) and subsequently analyzed using MALDI Bruker Real-Time Classification 3.1 software equipped with the BDAL database (Bruker Daltonics) composed of 6,903 reference spectra combined with verified local spectra from National Veterinary Institute, Kongens Lyngby, Denmark. The software compares the 10 closest spectra in the database to the entry; because expansion of the Bruker BDAL database is an ongoing process, local spectra were generated from isolates obtained by the Diagnostic laboratory at Technical University of Denmark and identified by biochemical methods or $16 \mathrm{~S}$ rDNA sequencing to meet the requirements for both animal and human reference spectra in the database. Improvement of the local database was conducted and isolates submitted as reference strains for the extended database were implemented. These stains were identified either by $16 \mathrm{~S}$ rDNA sequencing or by biochemical methods, as described by Andresen et al. (2005). The 47 custom main spectra were created according to Nonnemann et al. (2013; Supplemental Table S1, https://doi.org/10.3168/2018 -14579).

The analysis for each isolate was run in triplicate. If the isolate was not identified to species level in the first run, it was subcultured and resubmitted for MALDITOF to exclude the reason of no identification due to handling of the samples and to confirm that the nonidentified isolates were either due to new species 
or to the limitations of the database. After 2 rounds of MALDI-TOF, the unidentified isolates were considered as no possible identification. A cutoff score $\geq 1.7$ was regarded as a reliable threshold for the bacterial identification of NAS at species-level according to Cameron et al. (2017a, 2018).

Identification by $16 S r D N A$ sequencing. A set of NAS isolates without possible identification by MALDI-TOF were subjected to $16 \mathrm{~S}$ rDNA sequencing for identification. Those NAS isolates were selected on the basis of having a cutoff threshold $<1.7$ in the triplicate runs of the 2 rounds of MALDI-TOF. One bacterial colony was suspended in $1 \mathrm{~mL}$ of PBS and centrifuged for $5 \mathrm{~min}$ at $10,000 \times \mathrm{g}$ at room temperature. The supernatant was removed and the pellet resuspended in $100 \mu \mathrm{L}$ of water. The sample was boiled for $10 \mathrm{~min}$ and immediately placed on ice. The lysate was centrifuged for $2 \mathrm{~min}$ at $20,000 \times g$ at room temperature. The concentration of the DNA was quantified on a NanoDrop ND-1000 Spectrophotometer (NanoDrop Technologies, Wilmington, DE) and adjusted to $50 \mathrm{ng} / \mu \mathrm{L}$.

The 16S rRNA gene was amplified by PCR in 2 separate products with primers $8 \mathrm{f}-804 \mathrm{r}$ (5'-AGAGTTTGATC(AC)TGGCTCAG-3' and 5'-GTATTACCGCGGCTGCTGG-3') and (5'-CCAGCAGCCGCGGTAATAC-3' and 5'-GTTACCTTGTTACGACTTCAC-3'). The amplification program was denaturation at $94^{\circ} \mathrm{C}$ for $6 \mathrm{~min}, 33$ cycles $94^{\circ} \mathrm{C}$ for 45 $\mathrm{s}, 56^{\circ} \mathrm{C}$ for $45 \mathrm{~s}$, and $72^{\circ} \mathrm{C}$ for $90 \mathrm{~s}$, with final extension at $72^{\circ} \mathrm{C}$ for $10 \mathrm{~min}$ in a reaction volume of 50 $\mu \mathrm{L}$. Amplified PCR products, 796 and $990 \mathrm{bp}$ expected length, respectively, were verified by E-Gel (Invitrogen, Carlsbad, CA). Forty microliters of PCR product was purified with MinElute PCR purification kit (Qiagen, Hilden, Germany) and eluted in $20 \mu \mathrm{L}$ of ethidium bromide buffer. The amplified $16 \mathrm{~s}$ rRNA gene was sequenced on an ABI 3130 Genetic analyzer using BigDye Terminator v3.1 Cycle Sequencing Kit (Applied Biosystems, Foster City, CA) according to manufacturer protocol (https://assets.thermofisher.com/TFS-Assets/ LSG/manuals/4337035_BDTv31CycSqKt_RUO_UG .pdf). The resulting sequences were compared with the described sequences by blasting with the GenBank database (http://www.ncbi.nlm.nih.gov) as previously described (Strube et al., 2015).

\section{Statistical Analysis}

A logistic mixed regression model with herd and cow treated as random intercept was performed to investigate if teat apex colonization with a specific NAS species increased the odds of IMI with the given species in the corresponding quarter. Therefore, different models were performed for each of the NAS IMI species recov- ered from the quarter milk samples. Statistical analysis was carried out in $\mathrm{R}$ version 3.3.3 (The $\mathrm{R}$ Foundation for Statistical Computing, Vienna, Austria). Results were considered significant if $P \leq 0.05$.

\section{RESULTS}

Out of 150 eligible cows, 16 quarters were excluded for being dry or sampled twice. Out of 284 quarters of 142 cows, 228 quarters harbored at least 1 NAS species $\geq 5 \mathrm{cfu} / 0.01 \mathrm{~mL}$ identified by culture. Table 1 shows the number and distribution of NAS isolates from milk and teat skin samples submitted to MALDI-TOF assay. Out of 511 culture isolates, $399(78 \%)$ were identified to species level by MALDI-TOF, whereas the remaining $112(22 \%)$ were not identified after 2 submissions to MALDI-TOF and were labeled as no possible identification. Out of the 399 isolates identified by MALDITOF, 373 (93\%) were successfully identified as NAS, whereas the remaining 26 isolates $(7 \%)$ were diagnosed to be other bacterial species such as Aerococcus viridans, Bacillus pumilus, Enterococcus saccharolyticus, Clostridium septicum and Corynebacterium casei (Table 1). Out of the 26 isolates identified as other bacteria, 1 originated from milk and 25 from teat skin. Out of 373 isolates, $28 \%$ were isolated from milk $(\mathrm{n}=105)$ and $72 \%$ from teat skin $(\mathrm{n}=268)$. In the first round of MALDI-TOF, $85 \%(98 / 115)$ of the submitted isolates were identified as from milk, whereas the corresponding percentage was much lower for isolates from teat skin $(62 \%, 245 / 396)$. In the second round, $47 \%(8 / 17)$ were identified from milk, whereas $32 \%(48 / 151)$ were from teat skin isolates. The number of isolates without possible identification after 2 rounds of MALDI-TOF from teat skin $(\mathrm{n}=103)$ was about 10 times higher than that the number of isolates from milk $(\mathrm{n}=9)$.

In total, MALDI-TOF identified 16 different NAS species, 15 species from teat skin and 10 species from milk (Table 2). In milk samples, S. epidermidis (49.5\%, $52 / 105)$ was the most frequently isolated NAS species, whereas $S$. arlettae and $S$. warneri $(1 / 105)$ were the least frequently isolated species. In teat skin swabs, $S$. equorum $(43.3 \%, 116 / 268)$ was the most common species, whereas $S$. vitulinus and $S$. warneri $(1 / 268)$ were the least frequently isolated species. Staphylococcus equorum was the most frequently isolated NAS species from both left front $(35.5 \%, 63 / 183)$ and right hind $(30 \%, 57 / 190)$ quarters. Teat apex colonization with S. chromogenes, S. equorum, S. cohnii, S. epidermidis, S. haemolyticus, and S. xylosus was not found to significantly increase the odds of IMI with these NAS species (Table 2). Eighteen isolates without identification by MALDI-TOF were successfully identified using sequencing analysis, where $89 \%(\mathrm{n}=16)$ were correctly 
Table 1. Number and distribution of non-aureus staphylococci (NAS) isolated from milk and teat skin of dairy cows in 8 dairy herds submitted to MALDI-TOF assay for species identification of NAS

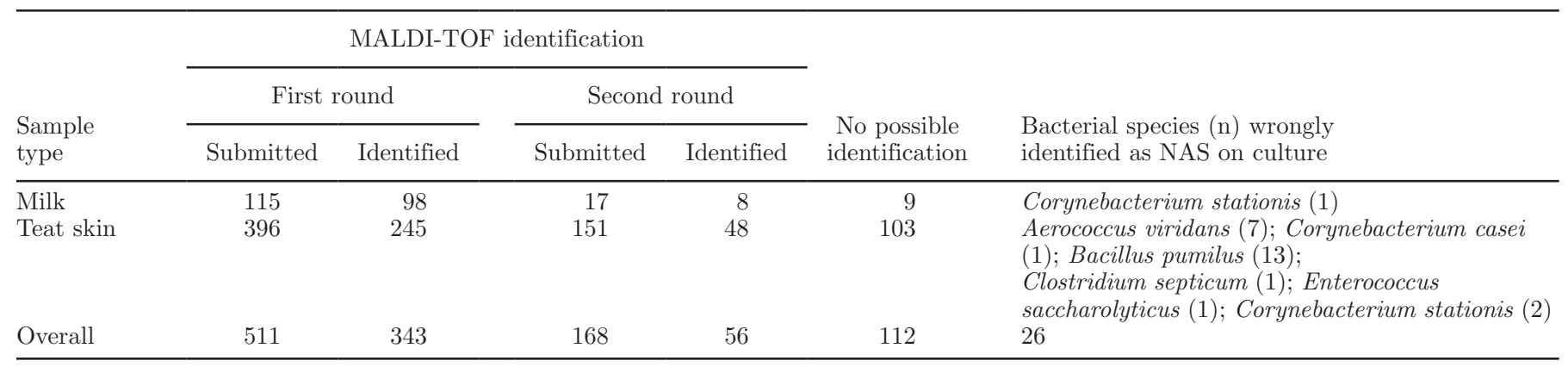

identified as NAS, whereas the other $11 \%(\mathrm{n}=2)$ were Corynebacterium stationis (Table 3 ).

\section{DISCUSSION}

To the best of our knowledge, this is the first study to evaluate the application of MALDI-TOF for identification and differentiation of NAS species on quarter level from milk and teat skin in dairy cows milked with automatic milking systems. Our findings showed that MALDI-TOF was able to identify $92 \%(106 / 115)$ of the submitted culture isolates originating from milk samples, indicating that it is a reliable assay for the rapid and accurate identification of NAS species from milk samples. This finding is similar to previous reports (Banach et al., 2016; Cameron et al., 2017, 2018; Goetz et al., 2017; Savage et al., 2017); for instance, Elbehiry et al. (2016) showed that MALDI-TOF correctly identified $100 \%(44 / 44)$ of NAS species isolated from milk, whereas Tomazi et al. (2014) demonstrated that sensitivity of MALDI-TOF for the identification of NAS isolated from milk was $95.4 \%$ in comparison to PCR-RFLP. Similarly, MALDI-TOF showed better performance $(93.2 \%)$ for identification of 234 NAS representing 20 different species as compared to Phoenix (75.6\%) and Vitek-2 (75.2\%; Dupont et al., 2010). Loonen et al., (2012) reported good performance of MALDI-TOF for identification of NAS, with a cor-

Table 2. Description of 16 species of non-aureus staphylococci (NAS) analyzed by MALDI-TOF and their association from aseptic quarter milk and teat skin habitats collected from 142 cows (284 quarters) in 8 dairy herds with automatic milking systems

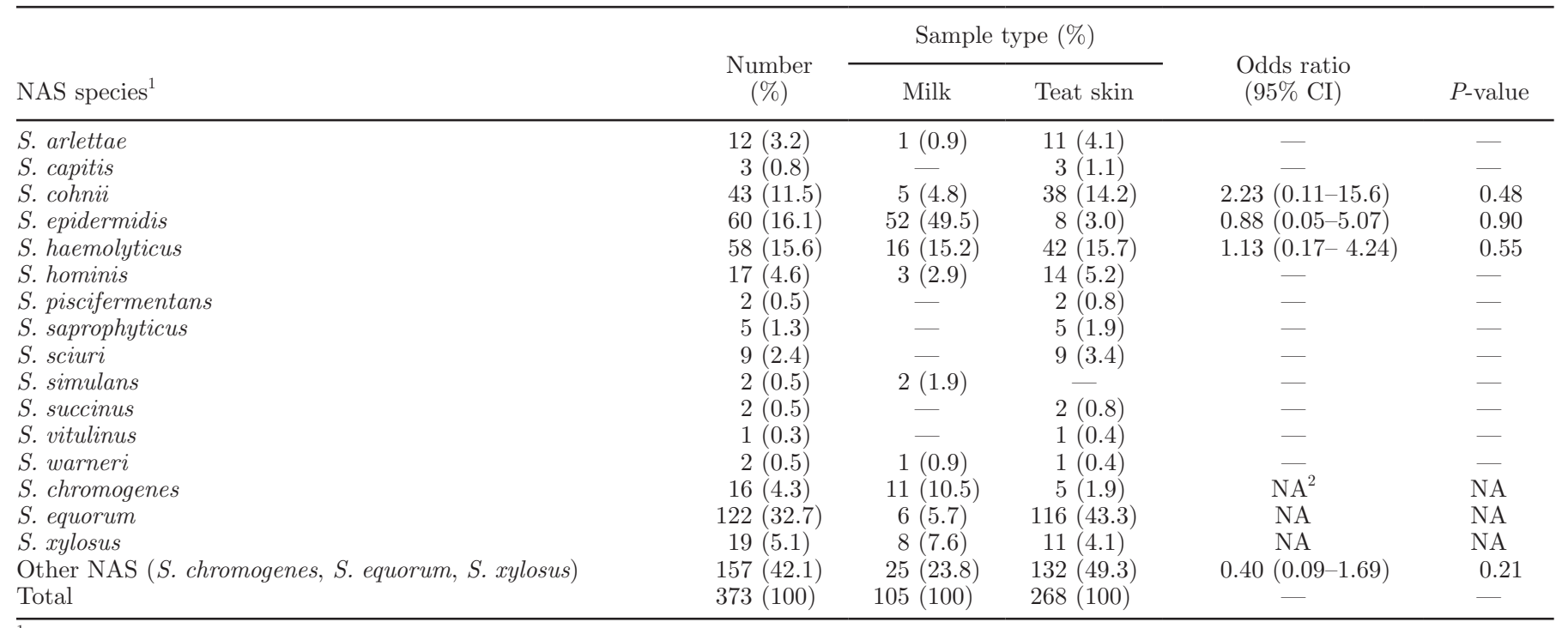

${ }^{1}$ Staphylococcus arlettae, S. warneri, and S. hominis were not considered in the statistical analysis because of the few number of observations $(<5)$, whereas S. capitis, S. piscifermentans, S. saprophyticus, S. sciuri, S. simulans, S. succinus, and S. vitulinus were not isolated from milk or teat skin.

${ }^{2} \mathrm{NA}=$ not applicable.

${ }^{3}$ Other NAS (S. chromogenes, S. equorum, S. xylosus) were grouped together for a valid statistical analysis because the mixed model does not work for each species separately. 
Table 3. Collection of bacterial isolates $(n=18)$ from bovine teat skin suspected to be non-aureus staphylococci (NAS) on culture and with no possible identification by MALDI-TOF after 2 rounds of submissions and were correctly identified by $16 \mathrm{~S}$ sequencing

\begin{tabular}{lc}
\hline $\begin{array}{l}\text { NAS species identified } \\
\text { by sequencing }\end{array}$ & Number (\%) \\
\hline Jeotgalicoccus psychrophilus & $1(5.6)$ \\
Corynebacterium stationis & $2(11.1)$ \\
Staphylococcus cohnii & $7(38.9)$ \\
Staphylococcus devriesei & $1(5.6)$ \\
Staphylococcus equorum & $3(16.7)$ \\
Staphylococcus arlettae & $2(11.1)$ \\
Staphylococcus vitulinus & $2(11.1)$ \\
Total & $18(100)$ \\
\hline
\end{tabular}

rect identification rate of $99.3 \%$. A lower identification percentage (78\%) was reported by Ayeni et al. (2017) based on 171 isolates (13 species) using MALDI-TOF. However, those authors found that a drawback in identifying NAS with MALDI-TOF was the inability to identify Staphylococcus gallinarum in their study, as it was absent from the MALDI-TOF database at the time of study.

After 2 rounds of triplicate MALDI-TOF the overall number of isolates remaining without possible identification was $22 \%(112 / 511)$, representing 103 from teat skin and 9 from milk. This is similar to Cameron et al. (2018), who demonstrated that 40 isolates were not identified to species level after the first round of duplicate MALDI-TOF, but identified all but 7 isolates after a second round of MALDI-TOF. In line with that finding, Pizauro et al. (2017) reported that not all NAS found in buffalo milk could be identified by MALDITOF. Additionally, Banach et al. (2016) reported that 6 isolates of NAS were not identified to species level by MALDI-TOF but were classified by means of routine bacteriological testing, and comprised S. sciuri (3 strains), S. xylosus (2 strains), and S. equorum (1 strain). As reported by others, some bacteria could not be detected by MALDI-TOF because the bacterial database is limited (Moussaoui et al., 2010; Barreiro et al., 2017; Cameron et al., 2017). Furthermore, some studies have shown that the conditions of bacterial growth, preparation of samples, number of reference strains, and version of the software Biotyper may be a reason for the variability of NAS identification (Benagli et al., 2011; Tomazi et al., 2014).

Our findings indicate that MALDI-TOF is a valuable tool for identification and typeability of NAS species from milk samples, but is less useful for identification of isolates from nonmilk samples. Furthermore, in both the first and second submissions, the performance of MALDI-TOF for identification of isolates originating from milk (85 and 47\%) was higher than for those originating from teat skin (62 and $32 \%$, respectively).
One possible explanation is that these unidentified bacteria from teat skin come from a natural teat skin microbiota (commensal bacteria), which have not been previously included in the BDAL database. For that reason, they may be out of interest of the microbiological diagnosticians, and therefore were not considered in the database of MALDI-TOF. Moreover, our findings showed that the vast majority of the unidentifiable NAS isolates originated from teat skin. A reasonable explanation could be that those isolates are new NAS species. Supré et al. (2010) classified 10 nonmotile, Gram stain-positive, CNS isolated from bovine milk and teat apices as $S$. devriesei $\mathrm{sp}$. nov using $16 \mathrm{~S}$ rRNA gene and 4 housekeeping genes (rpoB, hsp60, tuf, and $d n a J)$ in combination with tRNA intergenic spacer length analysis. Another reason is that these isolates could be known NAS species but are not included in our BDAL database. It may be worth mentioning that the database of MALDI-TOF we used is not based solely on the commercial version of the BDAL database. Our database was updated regularly because the assay was being used on research and routine diagnostic service purposes for identification and differentiation of bacterial pathogens in different samples types from both human and animals. We hypothesized that adding additional microbial spectra, the main spectra for some staphylococci species, will improve the identification capacity of MALDI-TOF both from milk and teat skin. Accordingly, Cameron et al. (2018) showed that using a custom reference spectra expanded database, which included an additional 13 in-house created reference spectra, isolates were identified by MALDI-TOF mass spectrometry with $99.2 \%(854 / 861)$ typeability and 99.4\% (849/854) accuracy.

Moreover, the BDAL database is mainly bacterial isolates originating from humans, and it has gradually extended to cover veterinary isolates (Tomazi et al., 2014). Randall et al. (2015) stated that the majority of reference spectra included in commercial MALDITOF databases are derived from human isolates and, consequently, small differences between human and animal isolates of the same bacterial species may influence the results obtained when testing some isolates from animals. Remarkably, $89 \%$ of 18 isolates without possible identification by MALDI-TOF were correctly identified as NAS using PCR, indicating that confirmation using nucleic acid tools is essential for those suspected NAS isolates of environmental origin. By examination of the genetic diversity among NAS species using molecular typing methods, Piessens et al. (2012) identified 5 genotypes among $S$. chromogenes in 6 dairy farms. Cameron et al. (2017) added that these genotypes would have different spectra and would require their own entry within the database. We updated the 
MALDI-TOF database on the basis of the findings in our study. Adding the spectra for 8 NAS species based on both prior knowledge of the species and results of the assessment of the database, we were able to eliminate the unidentified risk from $8 \%$ unidentified to $0 \%$ unidentified. Therefore, in future studies, we will expect better agreement in the performance of MALDI-TOF between teat skin and milk samples.

Consequently, MALDI-TOF is a valuable routine diagnostic tool for identification and differentiation of mastitis pathogens, but it has some limitations with regard to different detection capacity depending on the bacterial species and limited database of pathogens (Moussaoui et al., 2010; Barreiro et al., 2017; Cameron et al., 2017). In line with that statement, our findings showed that the isolates without possible identification by MALDI-TOF were successfully identified by $\mathrm{PCR}$, and sequencing analysis confirming the limited database of MALDI-TOF. However, the database can continuously be expanded to accommodate new species and spectra. Furthermore, the MALDI-TOF assay depends on initial microbiological culture, which is time-consuming and laborious (i.e., plate preparation, sterilization of materials, time of incubation, biochemistry tests; Barreiro et al., 2010; Cameron et al., 2017). Additionally, the reading is not constant and differs by changing the cutoff (identification score) for specieslevel identification (Barreiro et al., 2017; Cameron et al., 2017), and extra rounds of identification may be necessary for achieving accurate identification as shown in our study. Moreover, some previous studies have shown that the conditions of bacterial growth, preparation of samples, number of reference strains or spectra, database, and version of the Biotyper may be a reason for the variability of NAS identification (Benagli et al., 2011; Tomazi et al., 2014). Out of the initially unidentifiable isolates on the first round of MALDI-TOF, our findings showed that the assay identified 8 of 17 (47\%; milk) and 48 of 151 (32\%; teat skin) on the second round of identification. A plausible argument could be related to the variation in the conditions of bacterial growth, extraction procedure, and handling and preparation of samples between the first and second rounds of MALDI-TOF. The MALDI-TOF assay may be sensitive to the sample preparations and handling due to individual variations. This may also explain some of the deviations between different rounds, supporting previous reports (Benagli et al., 2011; Tomazi et al., 2014).

We noticed that NAS isolates originating from teat skin might require extra rounds for identification by MALDI-TOF compared with those originating from milk. That phenomenon is supported by the markedly high number of isolates from teat skin remaining unidentifiable after the first and second rounds of identi- fication. A possible explanation could be that bacterial isolates from the environment may have developed an extra layer or capsule of protein material as a mean of protection against unfavorable environmental conditions.

As a culture-dependent assay, MALDI-TOF relies on direct analysis of proteins from bacterial cell extracts of the reference strains included in the database (Liang et al., 1996). Thus, when a given NAS strain is tested, the species of the reference strain with the closest match is retained for identification of the tested strain (Ayeni et al., 2017). Therefore, an up-to-date database is essential for bacterial identification, and more spectra of appropriate reference strains of NAS should be added to the database for accurate identification (van Veen et al., 2010; Cameron et al., 2017). The same conclusion was supported by Murugaiyan et al. (2014) and Randall et al. (2015), who reported that the ongoing supplementation of the Bruker database library should further improve the utility of MALDI-TOF in routine veterinary diagnostic laboratories. Murugaiyan et al. (2014) demonstrated that 17 isolates initially diagnosed as Staphylococcus intermedius with the current content of the BDAL database were identified as Staphylococcus pseudintermedius by applying the in-house reference spectra extended version, indicating that updating the reference spectra library allowed species identification of NAS.

\section{CONCLUSIONS}

The MALDI-TOF assay provides a valuable and efficient platform for identification and typeability of NAS species from aseptically collected quarter milk samples; MALDI-TOF may be used for identification of NAS species from teat skin swabs. However, confirmation using nucleic acid-based tools is essential for accurate identification of some NAS species and strains.

\section{ACKNOWLEDGMENTS}

The study was part of the research project STOPMAST financed by the Danish Milk Levy Foundation (Aarhus, Denmark). We gratefully acknowledge the efforts of Nanna Skjølstrup and Louise Mathiasen for their help with sampling and examination of samples by bacterial culture. Thanks to the Danish farmers for their help and making their cows available for our study. Thanks to the milk quality technicians at SEGES (Aarhus, Denmark) helping taking milk samples and to the laboratory technicians for their technical and logistic support. Carsten Enevoldsen (Department of Veterinary and Animal Sciences, University of Copenhagen, Frederiksberg, Denmark) is acknowledged for 
his contribution in proofreading of this work. Yasser Mahmmod was supported by the Islamic Development Bank Merit Scholarship Program (IDB-MSP), Jeddah, Saudi Arabia.

\section{REFERENCES}

Andresen, L. O., P. Ahrens, L. Daugaard, and V. Bille-Hansen. 2005. Exudative epidermitis in pigs caused by toxigenic Staphylococcus chromogenes. Vet. Microbiol. 105:291-300.

Ayeni, F. A., C. Andersen, and N. Nørskov-Lauritsen. 2017. Comparison of growth on mannitol salt agar, matrix-assisted laser desorption/ionization time-of-flight mass spectrometry, VITEK ${ }^{\circledR} 2$ with partial sequencing of $16 \mathrm{~S}$ rRNA gene for identification of coagulase-negative staphylococci. Microb. Pathog. 105:255-259.

Banach, T., M. Bochniarz, P. Łyp, Ł. Adaszek, W. Wawron, B. Furmaga, M. Skrzypczak, J. Ziętek, and S. Winiarczyk. 2016. Application of matrix-assisted laser desorption ionization time-of-flight mass spectrometry for identification of coagulase-negative staphylococci isolated from milk of cows with subclinical mastitis. Pol. J. Vet. Sci. 19:627-632.

Barreiro, J. R., C. R. Ferreira, G. B. Sanvido, M. Kostrzewa, T. Maier, B. Wegemann, V. Böttcher, M. N. Eberlin, and M. V. dos Santos. 2010. Short communication: Identification of subclinical cow mastitis pathogens in milk by matrix-assisted laser desorption/ionization time-of-flight mass spectrometry. J. Dairy Sci. 93:5661-5667.

Barreiro, J. R., J. L. Gonçalves, P. A. Braga, A. G. Dibbern, M. N. Eberlin, and M. V. dos Santos. 2017. Non-culture-based identification of mastitis-causing bacteria by MALDI-TOF mass spectrometry. J. Dairy Sci. 100:2928-2934.

Benagli, C., V. Rossi, M. Dolina, M. Tonolla, and O. Petrini. 2011. Matrix-assisted laser desorption ionization-time of flight mass spectrometry for the identification of clinically relevant bacteria. PLoS One 6:e16424.

Bizzini, A., C. Durussel, J. Bille, G. Greub, and G. Prod'hom. 2010. Performance of matrix-assisted laser desorption/ionization-time of flight mass spectrometry for identification of bacterial strains routinely isolated in a clinical microbiology laboratory. J. Clin. Microbiol. 48:1549-1554.

Braem, G., S. De Vliegher, B. Verbist, M. Heyndrickx, F. Leroy, and L. De Vuyst. 2012. Culture-independent exploration of the teat apex microbiota of dairy cows reveals a wide bacterial species diversity. Vet. Microbiol. 157:383-390.

Braem, G., S. De Vliegher, B. Verbist, V. Piessens, E. Van Coillie, L. De Vuyst, and F. Leroy. 2013. Unraveling the microbiota of teat apices of clinically healthy lactating dairy cows, with special emphasis on coagulase-negative staphylococci. J. Dairy Sci. 96:1499-1510.

Cameron, M., H. W. Barkema, J. De Buck, S. De Vliegher, M. Chaffer, J. Lewis, and G. P. Keefe. 2017. Identification of bovine-associated coagulase-negative staphylococci by matrix-assisted laser desorption/ionization time-of-flight mass spectrometry using a direct transfer protocol. J. Dairy Sci. 100:2137-2147.

Cameron, M., J. Perry, J. R. Middleton, M. Chaffer, J. Lewis, and G. P. Keefe. 2018. Evaluation of MALDI-TOF mass spectrometry and a custom reference spectra expanded database for the identification of bovine-associated coagulase-negative staphylococci. J. Dairy Sci. 101:590-595.

Capurro, A., K. Artursson, K. P. Waller, B. Bengtsson, H. EricssonUnnerstad, and A. Aspan. 2009. Comparison of a commercialized phenotyping system, antimicrobial susceptibility testing, and tuf gene sequence-based genotyping for species-level identification of coagulase-negative staphylococci isolated from cases of bovine mastitis. Vet. Microbiol. 134:327-333.

De Visscher, A., S. Piepers, F. Haesebrouck, and S. De Vliegher. 2016. Intramammary infection with coagulase-negative staphylococci at parturition: Species-specific prevalence, risk factors, and effect on udder health. J. Dairy Sci. 99:6457-6469.
De Visscher, A., K. Supré, F. Haesebrouck, R. N. Zadoks, V. Piessens, E. Van Coillie, S. Piepers, and S. De Vliegher. 2014. Further evidence for the existence of environmental and host-associated species of coagulase-negative staphylococci in dairy cattle. Vet. Microbiol. 172:466-474.

Dupont, C., V. Sivadon-Tardy, E. Bille, B. Dauphin, J. L. Beretti, A. S. Alvarez, N. Degand, A. Ferroni, M. Rottman, J. L. Herrmann, X. Nassif, E. Ronco, and E. Carbonnelle. 2010. Identification of clinical coagulase negative staphylococci isolated in microbiology laboratories by MALDI-TOF mass spectrometry and two automates. Clin. Microbiol. Infect. 16:998-1004.

Elbehiry, A., M. Al-Dubaib, E. Marzouk, S. Osman, and H. Edrees. 2016. Performance of MALDI biotyper compared with Vitek ${ }^{\mathrm{TM}} 2$ compact system for fast identification and discrimination of Staphylococcus species isolated from bovine mastitis. MicrobiologyOpen 5:1061-1070.

Falentin, H., L. Rault, A. Nicolas, D. S. Bouchard, J. Lassalas, P. Lamberton, J. M. Aubry, P. G. Marnet, Y. Le Loir, and S. Even. 2016. Bovine teat microbiome analysis revealed reduced alpha diversity and significant changes in taxonomic profiles in quarters with a history of mastitis. Front. Microbiol. 7:480.

Fox, L. K., and R. J. Norell. 1994. Staphylococcus aureus colonization of teat skin as affected by postmilking teat treatment when exposed to cold and windy conditions. J. Dairy Sci. 77:2281-2288.

Goetz, C., Y. D. N. Tremblay, D. Lamarche, A. Blondeau, A. M. Gaudreau, J. Labrie, F. Malouin, and M. Jacques. 2017. Coagulase-negative staphylococci species affect biofilm formation of other coagulase-negative and coagulase-positive staphylococci. J. Dairy Sci. 100:6454-6464.

Gonçalves, J. L., T. Tomazi, J. R. Barreiro, P. A. Braga, C. R. Ferreira, J. P. Araújo Junior., M. N. Eberlin, and M. V. dos Santos. 2014. Identification of Corynebacterium spp. isolated from bovine intramammary infections by matrix-assisted laser desorption ionization-time of flight mass spectrometry. Vet. Microbiol. 173:147-151.

Kliem, M., and S. Sauer. 2012. The essence on mass spectrometry based microbial diagnostics. Curr. Opin. Microbiol. 15:397-402.

Leroy, F., E. Van Coillie, G. Braem, V. Piessens, B. Verbist, L. De Vuyst, and S. De Vliegher. 2015. Short communication: Subtyping of Staphylococcus haemolyticus isolates from milk and corresponding teat apices to verify the potential teat-skin origin of intramammary infections in dairy cows. J. Dairy Sci. 98:7893-7898.

Liang, X., K. Zheng, M .G. Qian, and D. M. Lubman. 1996. Determination of bacterial protein profiles by matrix-assisted laser desorption/ionization mass spectrometry with high-performance liquid chromatography. Rapid Comm. Mass Spectrom. 10:1219-1226.

Loonen, A.J.M., A.R. Jansz, J.N.B. Bergland, M. Valkenburg, P.F.G. Wolffs, and A.J.C. van den Brule. 2012. Comparative study using phenotypic, genotypic, and proteomics methods for identification of coagulase-negative staphylococci. J. Clin. Microbiol. 50:14371439.

Mahmmod, Y. S., I. C. Klaas, L. Svennesen, K. Pedersen, and H. Ingmer. 2018. Communications of Staphylococcus aureus and nonaureus Staphylococcus species from bovine intramammary infections and teat apex colonization. J. Dairy Sci. 101:7322-7333.

Moussaoui, W., B. Jaulhac, A. M. Hoffmann, B. Ludes, M. Kostrzewa, P. Riegel, and G. Prévost. 2010. Matrix-assisted laser desorption ionization time-of-flight mass spectrometry identifies $90 \%$ of bacteria directly from blood culture vials. Clin. Microbiol. Infect. $16: 1631-1638$.

Murugaiyan, J., B. Walther, I. Stamm, Y. Abou-Elnaga, S. Brueggemann-Schwarze, S. Vincze, L. H. Wieler, A. Lubke-Becker, T. Semmler, and U. Roesler. 2014. Species differentiation within the Staphylococcus intermedius group using a refined MALDI-TOF MS database. Clin. Microbiol. Infect. 20:1007-1015.

Nagy, E., M. Abrók, N. Bartha, L. Bereczki, E. Juhász, G. Kardos, K. Kristóf, C. Miszti, and E. Urbán. 2014. Special application of matrix-assisted laser desorption ionization time-of-flight mass spectrometry in clinical microbiological diagnostics. Orv. Hetil. 155:1495-1503. 
National Mastitis Council. 1999. Laboratory Handbook on Bovine Mastitis. National Mastitis Council, Madison, WI.

Nonnemann, B., M. Tvede, and T. Bjarnsholt. 2013. Identification of pathogenic microorganisms directly from positive blood vials by matrix-assisted laser desorption/ionization time of flight mass spectrometry. APMIS 121:871-877.

Paduch, J. H., E. Mohr, and V. Kromker. 2013. The association between bedding material and the bacterial counts of Staphylococcus aureus, Streptococcus uberis and coliform bacteria on teat skin and in teat canals in lactating dairy cattle. J. Dairy Res. 80:159-164.

Park, J. Y., L. K. Fox, K. S. Seo, M. A. McGuire, Y. H. Park, F. R. Rurangirwa, W. M. Sischo, and G. A. Bohach. 2011. Comparison of phenotypic and genotypic methods for the species identification of coagulase-negative staphylococcal isolates from bovine intramammary infections. Vet. Microbiol. 147:142-148.

Piepers, S., G. Opsomer, H. W. Barkema, A. de Kruif, and S. De Vliegher. 2010. Heifers infected with coagulase-negative staphylococci in early lactation have less cases of clinical mastitis and a higher milk production in their first lactation than non-infected heifers. J. Dairy Sci. 93:2014-2024.

Piessens, V., S. De Vliegher, B. Verbist, G. Braem, A. Van Nuffel, L. De Vuyst, M. Heyndrickx, and E. Van Coillie. 2012. Intra-species diversity and epidemiology varies among coagulase-negative Staphylococcus species causing bovine intramammary infections. Vet. Microbiol. 155:62-71.

Pizauro, L. J. L., C. C. de Almeida, G. A. Soltes, D. Slavic, O. D. Rossi-Junior, F. A. de Avila, L. F. Zafalon, and J. I. MacInnes. 2017. Species level identification of coagulase negative Staphylococcus spp. from buffalo using matrix-assisted laser desorption ionizationtime of flight mass spectrometry and cydB real-time quantitative PCR. Vet. Microbiol. 204:8-14.

Pyörälä, S., and S. Taponen. 2009. Coagulase-negative staphylococciEmerging mastitis pathogens. Vet. Microbiol. 134:3-8.

Quirk, T., L. K. Fox, D. D. Hancock, J. Capper, J. Wenz, and J. Park. 2012. Intramammary infections and teat canal colonization with coagulase-negative staphylococci after postmilking teat disinfection: Species-specific responses. J. Dairy Sci. 95:1906-1912.

Randall, L. P., F. Lemma, M. Koylass, J. Rogers, R. D. Ayling, D. Worth, M. Klita, A. Steventon, K. Line, P. Wragg, J. Muchowski, M. Kostrzewa, and A. M. Whatmore. 2015. Evaluation of MALDIToF as a method for the identification of bacteria in the veterinary diagnostic laboratory. Res. Vet. Sci. 101:42-49.

Sampimon, O. C., R. N. Zadoks, S. De Vliegher, K. Supré, F. Haesebrouck, H. W. Barkema, J. Sol, and T. J. G. M. Lam. 2009. Performance of API Staph ID 32 and Staph-Zym for identification of coagulase-negative staphylococci isolated from bovine milk samples. Vet. Microbiol. 136:300-305.

Savage, E., S. Chothe, V. Lintner, T. Pierre, T. Matthews, S. Kariyawasam, D. Miller, D. Tewari, and B. Jayarao. 2017. Evaluation of three bacterial identification systems for species identification of bacteria isolated from bovine mastitis and bulk tank milk samples. Foodborne Pathog. Dis. 14:177-187.
Schukken, Y. H., R. N. González, L. L. Tikofsky, H. F. Schulte, C. G. Santisteban, F. L. Welcome, G. J. Bennett, M. J. Zurakowski, and R. N. Zadoks. 2009. CNS mastitis: Nothing to worry about? Vet. Microbiol. 134:9-14.

Singhal, N., M. Kumar, P. K. Kanaujia, and J. S. Virdi. 2015. MALDITOF mass spectrometry: an emerging technology for microbial identification and diagnosis. Front. Microbiol. 6:791.

Strube, M. L., H. C. Ravn, H. C. Ingerslev, A. S. Meyer, and M. Boye. 2015. In situ prebiotics for weaning piglets: in vitro production and fermentation of potato galacto-rhamnogalacturonan. Appl. Environ. Microbiol. 81:1668-1678.

Supré, K., S. De Vliegher, I. Cleenwerck, K. Engelbeen, S. Van Trappen, S. Piepers, O. C. Sampimon, R. N. Zadoks, P. De Vos, and F. Haesebrouck. 2010. Staphylococcus devriesei sp. nov., isolated from teat apices and milk of dairy cows. Int. J. Syst. Evol. Microbiol. 60:2739-2744.

Supré, K., F. Haesebrouck, R. N. Zadoks, M. Vaneechoutte, S. Piepers, and S. De Vliegher. 2011. Some coagulase-negative Staphylococcus species affect udder health more than others. J. Dairy Sci. 94:2329-2340.

Taponen, S., S. Nykäsenoja, T. Pohjanvirta, A. Pitkälä, and S. Pyörälä. 2016. Species distribution and in vitro antimicrobial susceptibility of coagulase-negative staphylococci isolated from bovine mastitic milk. Acta Vet. Scand. 58:12.

Taponen, S., H. Simojoki, M. Haveri, H. D. Larsen, and S. Pyörälä 2006. Clinical characteristics and persistence of bovine mastitis caused by different species of coagulase-negative staphylococci identified with API or AFLP. Vet. Microbiol. 115:199-207.

Thorberg, B. M., M. L. Danielsson-Tham, U. Emanuelson, and K. Persson Waller. 2009. Bovine subclinical mastitis caused by different types of coagulase-negative staphylococci. J. Dairy Sci. 92:4962-4970.

Tomazi, T., J. L. Gonçalves, J. R. Barreiro, P. A. de Campos Braga, L. F. Prada e Silva, M. N. Eberlin, and M. V. dos Santos. 2014. Identification of coagulase-negative staphylococci from bovine intramammary infection by matrix-assisted laser desorption ionizationtime of flight mass spectrometry. J. Clin. Microbiol. 52:1658-1663.

van Veen, S.Q., E.C. Claas, and E.J. Kuijper. 2010. High-throughput identification of bacteria and yeast by matrix-assisted laser desorption ionization time of flight mass spectrometry in conventional medical microbiology laboratories. J. Clin. Microbiol. 48:900-907.

Vanderhaeghen, W., S. Piepers, F. Leroy, E. Van Coillie, F. Haesebrouck, and S. De Vliegher. 2014. Invited review: Effect, persistence, and virulence of coagulase-negative Staphylococcus species associated with ruminant udder health. J. Dairy Sci. 97:5275-5293.

Watts, J. L., C. H. Ray, and P. J. Washburn. 1991. A convenient method for differentiation of coagulase-negative staphylococci isolated from bovine mammary glands. J. Dairy Sci. 74:426-428.

Zadoks, R. N., and J. L. Watts. 2009. Species identification of coagulase-negative staphylococci: Genotyping is superior to phenotyping. Vet. Microbiol. 134:20-28. 